\title{
Flipping the classroom
}

\section{Students' perceptions from an introductory \\ sociology course}

\author{
Ann Ward, Aja Antoine and Wendy Cadge
}

\begin{abstract}
This article describes one approach to flipping an introductory sociology course. To encourage students to practice 'doing' sociology, we designed a flipped classroom that included a 'pay to play' model, small group work and an emphasis on active learning during class time. With this course design, we linked in-class active learning with outside prework so that students could engage with critical sociological concepts and apply those concepts in practice. With this flipped design, the instructors observed that students were deeply engaged with the course topics and expressed positive perceptions of their learning and growth over the semester. As the landscape of university instruction shifts, this course design model may assist instructors looking to foster active and engaged learning remotely.
\end{abstract}

\section{KEYWORDS}

active learning, flipped classrooms, introductory sociology, remote learning

Instructors teach some form of introductory sociology course at a wide range of colleges and universities. Multiple textbooks map the content of introductory sociology classes, and instructors prepare courses in introductory sociology every semester. Scholars have explored pedagogical approaches to introductory courses in sociology in online, in-person, and hybrid models (Auster 2016; Belet 2018; Luna and Winters 2017). A robust body of literature considers innovative teaching strategies for introductory sociology classes, including thematically focused course design (Howard et al. 2014), recursive exercises that encourage students to develop sociological imaginations (Whitaker 2017), and photo-elicitation projects that simultaneously develop 
students' sociological imaginations while also informing instructors about unfamiliar social contexts (Mount 2018).

This article explores the opportunities and limitations of teaching introductory sociology using flipped pedagogy - an approach in which content is primarily delivered outside of the classroom and students spend in-class time on problem sets and interactive learning (Naccarato and Karakok 2015; Schwartz 2014; Tomory and Watson 2015). In this article, we share lessons learned from designing a flipped classroom, focusing primarily on the structures we implemented to facilitate active learning. Using a combination of small group work and outside work that relied on a 'pay to play' model, we encouraged students to move beyond information retention and towards 'doing' sociology. These active learning exercises that we executed during class time provided a significant opportunity for this kind of learning. One primary space where active learning activities took place was in small assigned groups. These groups allowed us to break up an otherwise large lecture-sized class and create space for smaller, more intimate learning teams.

Additionally, to ensure that students could participate in the active learning activities designed for the small groups, we had to be sure they understood the key course concepts. Because the flipped classroom delivers most of the course content outside of class time, we also created a 'pay to play' model to ensure students were coming to class prepared and with a general understanding of the materials. Together, the active learning activities, small groups, and the 'pay to play' model allowed us to design a course where students were encouraged to both learn about and do Sociology.

The decision to 'flip' our introductory sociology course was rooted in the desire to encourage student participation in the course and make it difficult for students to passively sit in class without engaging with one another or the material. With this goal in mind, a flipped course design was uniquely situated to facilitate active learning in class. Because we delivered the majority of the content outside of class, students used the content that they had learned the night before during class time. In past experiences teaching introductory courses, Author 2 found that the parts of the semester that students enjoyed most were hands-on, active learning exercises. She also found that during these activities, students showed significant engagement with the course learning goals. A flipped structure provided an innovative format to build these active learning activities into the class.

In this article, we describe how we flipped the course, evaluate assessment data based on student perception, and explore the opportunities and 
limitations of this approach. We describe the principles we utilised to design this class and share the feedback we gathered from students. Flipped classrooms facilitate collaborative, dynamic, active learning activities that allow students to try out 'doing sociology', which is especially important in an era of collective reassessment of how universities prepare students for their professional goals.

\section{Literature review}

While there is some debate over terminology (Fuster 2016), most scholars agree that the flipped classroom is a form of blended learning in which students do most of the 'traditional learning' online or outside of the classroom and spend in-class time participating in various types of active learning activities (Horn 2013; McNally et al. 2017). The Flipped Learning Network has distinguished between a flipped classroom and flipped learning (FLN 2014), claiming that while many teachers flip the classroom by requiring students to do work outside of class, to engage in flipped learning, the instructor must implement a flexible environment, a learner-centred culture, and intentional content that makes sense in the context of the course. While we understand the need to distinguish between simply assigning materials outside of class and engaging in rigorous course design and implementation, we use both terms here for audiences less familiar with definitional nuances.

Debates around defining terms are not the only thing instructors have yet to agree on regarding the flipped classroom. Marilla Svinicki (2013) asks the question, 'Are flipped classrooms really something new?' She claims that while flipped classrooms capitalise on active learning opportunities, allow instructors to use their expertise in valuable ways, and set important expectations around coming to class prepared, there is actually nothing new about this kind of course design. She argues that what would make a flipped classroom new is if students could use information in a face-to-face class. To promote doing sociology, we attempted to use active learning activities to empower students to use the information from the course, not just receive it.

As faculty continue to explore the most effective approaches to teaching and learning in higher education, flipping the classroom is an increasingly popular approach to course design, particularly in the Science, Technology, Engineering, and Mathematics (STEM) fields. Scholars in STEM fields have been considering the opportunities and limitations of flipped classrooms for years. Recent publications examine the practical challenges of locating ap- 
propriate on-campus space for these types of courses (Baepler et al. 2014) and discuss navigating faculty and students who are 'flip resistors' or 'flip endorsers' (McNally et al. 2017). Other educators challenge STEM scholars to be more rigorous about their reasons for flipping classrooms in the first place (Heyborne and Perrett 2016). Interestingly, fewer social scientists have written about flipping social science classrooms. Those that have focus on the advantages and the challenges of this approach, like the ability for faculty to integrate scaffolded and recursive activities into the course (Sardi 2018), the possibility that a flipped classroom could exacerbate existing inequalities (Horn 2013), and the challenge of navigating students' culturally constructed understanding of what college learning 'should be' (Forsey et al. 2013). We see great promise in the flipped classroom approach, though social scientists are still learning how to manage its challenges and possibilities.

Despite the push from scholars like Patricia Roehling and colleagues (2017) and Yvonne Luna and Stephanie Winters (2017) for more evaluation of flipped social science classrooms, there is limited information for faculty outside STEM fields who wish to design a course this way. Articles that focus on flipped learning in the social sciences spotlight certain types of activities or teaching techniques like screencasting (Auster 2016), the PTA (prioritisation, translation, and analogisation) model of writing (Sardi 2018) or integrating the flipped classroom into a Massive Online Open Courses or MOOC (Forsey et al. 2013). We contribute to this literature by outlining how we structured our flipped classroom over the whole semester and evaluating how those choices impacted our students' perceptions of their learning.

\section{Our context and approach}

We flipped the Introductory Sociology course at Brandeis University, a midsized research university outside of Boston. With 3,500 undergraduates and 2,000 graduate students, faculty work intensively with undergraduates, particularly in the social sciences. The Sociology Department requires all majors to take an introductory course. Many first- and second-year students do so to complete their general education requirements in the social sciences. The introductory course is entitled 'Order and Change in Society' and is offered in the fall and spring semesters, with enrolments ranging from thirty-five to one hundred. We taught this course in the fall of 2018, and we had sixty-eight students on our class roster, coming from all years and a range of actual or intended majors. 
Over the last twenty years, several faculty have taught the introductory class, and the instructor's learning goals and assignments vary. We began preparing our flipped course by identifying learning goals present across course syllabi spanning from the early 2000s to the present. We also spoke to department faculty about what they considered the most central learning goals to guide our flipped design. We then structured the course around these learning goals (see Table 1).

As a team, the authors thought focusing on these goals in a flipped context would encourage students to do sociology and make it difficult for them not to be engaged in the classroom and assignments. With support from a teaching grant and an instructional designer, we reframed the learning goals for introductory sociology to reflect our emphasis on these particular objectives. After setting the learning goals, we began developing the course structure and building out the flipped classroom week by week.

Table 1. Set learning goals for Order and Change in Society Fall 2019

\begin{tabular}{|l|l|}
\hline $\begin{array}{l}\text { Learning } \\
\text { Goal }\end{array}$ & Description of the Learning Goal \\
\hline$\# 1$ & $\begin{array}{l}\text { Describe how sociologists conceive of questions and problems using } \\
\text { your 'sociological imagination'. Use that imagination to develop a so- } \\
\text { ciologically informed self-awareness and to describe situations in the } \\
\text { world in sociological terms. }\end{array}$ \\
\hline$\# 2$ & $\begin{array}{l}\text { Define social structure and analyse how structural forces shape peo- } \\
\text { ple's daily experiences and opportunities in patterned ways. Define } \\
\text { agency and understand when, why, and how people have agency or } \\
\text { choice in daily life. }\end{array}$ \\
\hline$\# 3$ & $\begin{array}{l}\text { Analyse several meanings of culture and describe how culture influ- } \\
\text { ences the ways people live and are socialised. Articulate how your life } \\
\text { has been shaped by the cultures in which you were raised and how } \\
\text { your experiences compare to someone who was raised in different } \\
\text { cultural contexts. }\end{array}$ \\
\hline$\# 4$ & $\begin{array}{l}\text { Present and analyse data about inequalities based on gender, race, } \\
\text { class and sexuality in the contemporary United States and describe } \\
\text { how inequalities are evident in particular case studies. Relate data } \\
\text { about inequality to questions of identity in a range of case studies. }\end{array}$ \\
\hline$\# 5$ & $\begin{array}{l}\text { Learn to more carefully listen, understand and engage with people } \\
\text { who are different from you along any number of axes. Develop more } \\
\text { personal comfort agreeing to disagree with others and holding that } \\
\text { disagreement in a professional rather than personal framework. }\end{array}$ \\
\hline
\end{tabular}




\section{Structure of the course}

When preparing a flipped classroom, the bulk of the work needs to be done before the start of the semester. We went to work planning and structuring the course in June to ensure it would be ready for the start of classes in September. In addition to our efforts to craft learning goals tailored to our department's brand of sociology and the flipped experience, we also developed and sequenced a syllabus and curated materials for content delivery. This introductory level class is a four-credit course that meets for fifty minutes, three times a week. It has no prerequisites and meets for fifteen weeks over one semester. To ensure that our students received materials in an order that made sense, we broke the fifteen-week course into topical sections that covered a broad scope of the discipline. These sections included weeks on culture and socialisation, race, class and gender, micro and macro levels of analysis, a case study about housing inequality, and an overview of sociology as a discipline to name a few. When selecting the assigned materials for each section, we drew from a variety of sources. In most flipped classrooms, the instructor records lectures for students to view outside of class. Instead, we required students to prepare for class by doing a range of activities, including reading books, op-eds and journal articles, watching videos and completing short exercises. To design the fifteen-week course, we curated the outside prework that we expected students to complete before class.

During this curation process, we found that many of the authors on our syllabus had excellent material that gave a face to a name and showed the students concrete examples of what sociology looks like in practice. Some weeks, we featured a broadly cited sociologist who had broken through to the mainstream public. We assumed these scholars would have more podcast appearances, public talks and other kinds of materials readily available. This was not always the case. We supplemented these readings with related news stories, videos, data sets, podcasts, or other online materials in instances where we could not find materials related to a specific author's work. This blend of materials allowed students to engage with crucial course concepts. After curating the materials for each class session, we set out to create appropriate assignments and fill out the rest of the syllabus.

In terms of our evaluation and assessment of students, grades broke down in a way that reflected the flipped classroom structure. Attendance was worth 10 per cent of the final grade, preparation for class in the form of prework was worth 20 per cent of the final grade, class participation was worth 10 per 
cent of the final grade and facilitating a student-led discussion was worth 10 per cent of the final grade. In terms of traditional assignments, we had two written assignments worth 10 per cent each, a third worth 15 per cent, and a final exam worth 15 per cent.

To assess attendance, one teaching assistant (TA) was responsible for taking attendance at the start of each class. Students were expected to come to every class and lost a point for each class they missed. A student who never missed a class would receive a full ten points, whereas a student who missed two classes would receive eight points. We allowed for flexibility with our attendance policy if a student could notify us of an absence a week in advance or in the case of an emergency. For class participation, we relied on the small group leaders to give their assessment of student engagement. For the most part, unless students were frequently absent or obviously disengaged, they received full credit for participation. We also provided students with clear guidelines to set expectations for the student-led discussions but kept it relatively flexible to encourage creativity and student empowerment. Finally, we evaluated class preparation using the 'pay to play' model, explained in detail in the following section.

Additionally, to uphold the flipped structure, we designed innovative and creative ways to assess students' learning over the semester that we did not grade but served as a marker for student learning and understanding. One of these assessments took the form of a 'flipped midterm' and a 'flipped final'. While students did receive a grade on their final exam and three other writing assignments, these flipped assessments were a low-stakes activity that served to prepare students for the graded versions. We wrote out approximately ten questions on flip chart paper and asked students to walk around in a circle, take five minutes per question, answer the question together as best as possible, and then move on to the next one. They were encouraged to build on previous answers given by other groups or challenge claims made in previous attempts to answer the question. We based our questions on content areas we covered in class and were linked back to our original course learning goals. In both the flipped midterm and the flipped final, we saw that most students could take the core concepts listed in the learning goals and apply them to the course materials and their personal experiences in both assessments.

We designed all these components of the introductory course to facilitate active learning and the doing of sociology. While this structure served us well, implementation can be flexible. Our rule of thumb when creating as- 
signments or 'pay to play' prework was to do what made the most sense for that week in the broader context of the course. For faculty interested in implementing this in a different context, this may serve as a starting point for developing a flipped introductory course. While developing a course structure and curating prework materials for the class created a strong foundation for our flipped classroom, we also had to implement specific mechanisms over the semester to ensure students had the opportunity to both learn sociology and practice doing it. This meant prioritising active learning in small groups and effectively preparing students before class so they could meaningfully engage in the activities.

\section{Active learning in class}

Rooted in the traditions of active learning (Baepler et al. 2014), the flipped classroom challenges students to produce and critically engage with knowledge (Eglitis et al. 2016). This relationship between flipped instruction and active learning was central to our decision to implement this kind of course structure. Jennifer Faust and Donald Paulson have defined active learning as 'any learning activity engaged in by students in a classroom other than listening passively to an instructor's lecture' (1998: 4). As Allison King's seminal piece on active learning reminds us, 'knowledge does not come packaged in books, or journals, or computer disks (or professors' and students' heads) to be transmitted intact from one to another. Those vessels contain information, not knowledge' (1993: 30). When designing our course, we took this reminder from King as a starting point and made sure learning was as an active process of dialogue, not a passive process of information transfer. At its core, the flipped classroom extends active learning through in-person and online instruction inside and outside of the classroom to encourage critical thinking skills.

We decided to leverage this connection between active learning and flipped instruction by designing in-class active learning activities implemented in small groups. We prioritised the application of sociological concepts and skills in all written work and class activities. This meant crafting daily activities for the class that connected the prework assigned to 'doing' sociology. Like the curating process, we created these activities before the semester started to ensure they made sense in the broader course structure. These activities ranged from group discussions, to coding children's books, to crafting a book review, to name a few examples. We recognised that this 
kind of course format was new to many students and that active learning can sometimes seem like an abdication of teaching responsibilities. To mitigate these challenges, we made it very clear on the first day of class that this would be a different kind of learning environment and that active learning would be central to the overall course design. Setting expectations early on and explaining why the class might feel different was an important way to prepare students to engage in active learning.

\section{Small group meetings}

Knowing that this was likely to be a comparatively large class in our institutional context, we organised students into small groups of ten. These small groups worked together on various weekly group activities throughout the semester. Three graduate TAs and three undergraduate peer TAs served as group leaders alongside the course instructor to conduct these small groups. These small group leaders served as facilitators rather than instructors and made space for each group to set their norms and expectations. We intentionally structured the role of the group leader this way so students could be at the centre of their learning. While leaders gave general directions and probed the group to engage further with core concepts, they often allowed students to control the flow and direction of the group's learning.

We organised the groups in alphabetical order. To pre-empt any issues in the small groups, we decided that the facilitators would swap midway through the semester. We made the decision to swap to account for any issues or challenges that could arise over the course of the semester. If a group was really struggling with the material or if a TA was having a difficult time, this swap would allow a more experienced instructor to help facilitate. When coordinating this swap, facilitators met and reflected on the group dynamic and learning that had gone on over the first six weeks of the semester. This allowed the primary instructor to switch into the group that seemed to be having the most challenging time but did not disrupt the positive group dynamics that had been forming. We did not experience any significant challenges in any of the small groups, so the swap ended up being random, but building this into the structure of the class allows for flexibility and management of small group dynamics.

These small groups enabled the students to learn together and get to know classmates. In an introductory class with a wide variety of majors and years, it brought students together who otherwise may have never been in 
contact with one another in a course setting. Bringing students together in these small groups also helped bring a discussion-based, small seminar feel to an otherwise large and potentially impersonal class. These small groups strengthened community ties in the classroom, providing a social resource to students, and added an additional layer of accountability to encourage student engagement. These groups also served as a primary space for implementing active learning activities that encouraged and empowered students to practice flexing their sociological imagination.

\section{'Pay to play'}

Finally, to ensure students were adequately prepared for the active learning in these small groups, we developed a 'pay to play' model that held students accountable to the prework and allowed us to keep track of students' progress, learning, and engagement with the course concepts. According to university guidelines, students should spend nine hours per week preparing for a four-credit class. For our introductory course, we asked students to use this time to complete all class prework. This prework was a combination of reading, watching, and listening to materials. We detailed the curation process for gathering these materials earlier in this article. In addition to assigned materials, we asked the students to complete a preparation check. We created these mini-assessments for each class, and the structure differed depending on the topics. Sometimes it took the form of a multiple-choice exercise. Other times, it was a few short answer questions, and sometimes it was one long discussion question. To keep all these components organised, we created a spreadsheet documenting the assigned prework, the corresponding 'pay to play' preparation check, and the in-class active learning activity for each class. The organisation and preparation of learning materials before the semester started was crucial to the overall success of the course.

We structured the syllabus and accompanying online course page so that every class meeting had prework due the night before. We expected these preparation checks would take no more than ten minutes if students had engaged with the prework materials. These low-stakes prework assignments were worth only two points per attempt but were worth 20 per cent of the overall grade. These preparation checks were assessed on completion, not on correctness. Each facilitator was responsible for reading and grading these preparation checks. If a student made an effort to complete the assessment, 
they received a two. If it were clear that the student did not engage with the prework, the student would receive a one. If students completely missed an assignment, they would receive a zero, and we could check-in and address any challenges students may be experiencing before it seriously impacted their grades.

Aside from assigning points based on completion, facilitators responded to each student by clarifying key concepts, asking additional questions, and taking the time to show students that this was not just busywork. This response took place over our online course platform, which has built-in tools like a quiz feature. If such tools are not available, it is also possible to ask students to keep and share a running document that the facilitator can comment on and edit. We called this our 'pay to play' model, and it helped us evaluate students' progress outside of class and ensure that they were prepared for the in-class active learning.

\section{An example}

To give a sense of what these three systems of accountability looked like in practice, we will provide an example in this section. During the first few weeks of class, we wanted to encourage students to think about how macro structures influence their everyday lives. Before class, students read an introductory article about communities and cities written by a sociologist and explored the websites of two cities close to the university, one of which is considerably wealthier than the other. Then, in line with the 'pay to play' model previously described, they were given a set of instructions that guided them through their exploration and a few questions that they were expected to answer. We asked students to think about a situation - like a child ready for kindergarten, a pothole, or a broken traffic light - and explore the resources in each city for getting assistance. We specifically asked them to find one policy from each city that would shape how their situation would be addressed. They were also asked to fill out a shared Google document before class, so students could see what their peers had found.

In class, students were divided into groups based on the topic they chose. While students normally stayed in their assigned groups, for this day, we allowed them to pick whatever topic they found most interesting to insert an opportunity for choice. We had groups focused on themes that emerged in responses: pets, snow or garbage removal, public gatherings, education, and so on. Students compared policies in each city in their small groups, 
illustrated these comparisons on flip chart paper, and talked about how macro structures influence these differences. We then had a gallery walk, where students walked around to see what each of the other groups found. At the end of class, we brought everyone back together. We debriefed on how each city's policies were evidence or factors in macro structures of inequality. Using these three core systems to structure our flipped design, we were able to make space for students to practice using the concepts, which was a central goal of this course.

\section{Materials and methods}

When we first designed this course, we knew that we wanted to gather information from students on their perceptions of the course. This data would help us discern if we would try the flipped classroom again. We also knew that we would not have any data from a 'traditional' introductory course for comparison. Despite this limitation, we still felt that collecting some data from students would provide us with helpful information and them the opportunity to give feedback on their learning experience. At the beginning of the semester, students were asked to take a non-graded 'pre-test' to gather information about their knowledge of key course concepts. Students completed the same set of questions as a 'post-test' at the end of the semester. This provided us with a set of data about student's perceptions of their learning that we used to evaluate the flipped classroom.

The pre-tests and post-test, which provided the best though not ideal, assessment data, asked students to respond to a set of Likert scale questions using a scale from one to five (one being strongly disagree, five being strongly agree). There were twenty questions in total. Of the sixty-eight students who were on our final course roster, forty-nine completed the pre- and post-test. (See Table 2 for all twenty questions.) We analysed this data by calculating the mean difference between the pre-test and the post-test, which gives us a preliminary look into the changes in students' perceptions over the semester. While we understand that because of the design of this study we are unable to attribute changes in perception to the flipped structure directly, this preliminary evidence serves as a call for further research about the flipped classroom in the social sciences.

In addition to the Likert scale questions, there was also an open-ended question at the end of the post-test. This question asked the students to respond to the prompt, 'What I got most out of this class was .... O Out of the 
Table 2. Pre/post-test questions thematically sorted by learning goals

\section{Pre/Post-Test Questions \\ Thematically Sorted by Learning Goals \\ Learning Goal One}

I know what sociology is.

I understand how to ask sociological research questions.

I feel confident asking and answering a sociological question.

\section{Learning Goal Two}

I can explain the difference between structure and agency.

\section{Learning Goal Three}

N/A

\section{Learning Goal Four}

I know what it means to say gender is a social construct.

3.90

4.94

I can explain what the federal poverty line is and where the calculation was developed.

I understand the purpose and daily work of the

Census Bureau.

I am aware of the history of asking about race on the

US Census.

I understand how eviction relates to poverty and inequality.

I can explain what it means to say the United States is a stratified society.

\section{Learning Goal Five}

I feel comfortable having conversations and debates with people who have different perspectives and beliefs than me.

\section{Research Methods}

I know what a unit of analysis is.

I know the difference between quantitative and qualitative research methods.

I feel confident working with different types of data.

I know what the strengths and weaknesses are of the ethnographic method.

\section{Miscellaneous}

I can identify three sociologists outside of Brandeis University.

I have an understanding of the micro, meso, and macro levels of social organization.

I know how to distinguish an empirical argument from a normative argument.

I often use what I have learned in school to make sense of the world around me.

I know how to find an empirical research article in a sociological database in the library.

\section{Pre-Test Post-Test Mean \\ Mean Mean Difference}

$\begin{array}{lll}3.45 & 4.65 & 1.20^{* *} \\ 2.67 & 4.39 & 1.71^{* *} \\ 2.67 & 4.46 & 1.79 * *\end{array}$

2.61

4.55

$1.94^{* *}$ 
sixty-eight students on the final class roster, fifty-two students responded to this question. For this article, the data collected in this section was invaluable. We coded this qualitative data inductively to uncover central themes. The three authors completed an initial code of these data to identify key themes in students' perceptions of the course and their learning throughout. We then coded the document a second time using these themes for a more systematic approach. In the following section, we discuss our findings from our data. Our preliminary assessment supports the results reported by other scholars on the efficacy of the flipped classroom approach.

\section{Discussion}

Using the data that we collected over the semester, we found many strengths of the flipped classroom. In our experience, students were deeply engaged with the material. Using our learning goals as markers of progress, we evaluated all of the data we collected within the context of these five goals to analyse what students learned over the semester.

As shown in Table 1, Learning Goal One reads: 'Students will be able to describe how sociologists conceive of questions and problems using your "sociological imagination". Use that imagination to develop a sociologically informed self-awareness and to describe situations in the world in sociological terms'. Between the start and end of the semester, students perceived that their sociological imaginations were strengthened. As previously mentioned, the post-test asked students an open-ended question, 'What I got most out of this class is.... About one-third of the students referenced their sociological imagination in some form and reported that learning to think like a sociologist was a central take-home lesson from the course. In the words of one student, 'I gained the ability to utilise a sociological imagination to assess the world around me and think about how an individual's agency relates to societal structures'. Another student claimed, 'As my first sociology class as a first-year, I was so impressed with this sociology class that it made me decide to major in Sociology. I learned even more about what sociological questions is [sic] and what sociology actually means and what [sociologists] study'. As one student wrote, '[I gained] the ability to recognise patterns and phenomena through a sociological lens as well as exposure to significant pieces of work by sociologists outside of Brandeis'. These shifts, along with their preand post-test responses and their success on assessments and in classroom activities, reinforced the idea that students understood conceptually what 
a sociological imagination was and felt that their sociological imagination had grown.

Learning Goals Two, Three, and Four are directly linked to the contentspecific learning goals for the course. These particular three learning goals are likely found in some version in most introductory courses. In addition to focusing on the sociological imagination, throughout the semester, we discussed structure, agency, and the types of research designs and sociological research questions that enable scholars and students to understand both. As seen in Table 1, Learning Goal Two states: 'Students will be able to define social structure and analyse how structural forces shape people's daily experiences and opportunities in patterned ways. Define agency and understand when, why, and how people have agency or choice in daily life'. Students' responses to the open-ended questions indicate that they found engaging with the concepts of structure and agency to be one of the more impactful elements of the course. One student claimed,

I think the most powerful part about this class is that it forces students to think about how certain things like eviction are actually heavily affected by the structure of society. It really opens your eyes to the fact that many things that seem separate from society are actually restricted or affected by it. And much of what you think you may have agency over is actually considerably affected by the structure of society.

Another student stated:

[I've gained] a better understanding of the world around me and how specific social structures shapes the world from the institutional level to social interactions. I now think more critically about inequality and feel that I have more information to make a stronger argument as to why and how people are systematically oppressed.

Not only do these statements indicate that students understood the concepts of structure and agency, but they also highlight how students have begun to use the concepts to make sense of the world around them.

The preliminary data collected from this course suggests that the flipped classroom structure facilitates this movement from understanding to the application of concepts. This classroom structure holds students accountable for the out-of-class prep work while also encouraging students' engagement in dynamic, active learning activities with their peers over the semester. 
Along with Learning Goals One and Two, our evidence suggests that the flipped classroom allowed students to engage with Learning Goal Five. As can be seen in Table 1, Learning Goal Five states: 'Students will be able to learn to more carefully listen, understand, and engage with people who are different from you along any number of axes. Develop more personal comfort agreeing to disagree with others and holding that disagreement in a professional rather than personal framework'. We structured the Introduction to Sociology course to set aside a significant amount of time for small group work in which students were encouraged to work through complex problems. These groups met during class time as part of the flipped classroom structure. The small groups allowed them to work through the previous night's homework as a collective by completing various in-class activities.

Students responded to the open-ended question about what they got most out of the class by claiming that discussion across differences was one of the most significant overall takeaways from the course. One student stated, 'Discussions with my peers allowed me to utilise language I read in our readings and become more comfortable vocalising my thoughts and experiences with difficult topics'. Another student mentions, 'Having open and honest discussions with my fellow classmates helped me hear new perspectives I had never heard before and allowed me to challenge some of my own ideas'. Finally, a student claimed that they gained 'a further understanding of the inequalities in America that are usually avoided in discussion, as well as an increased ability to learn how to have/start these discussions'. These findings indicate that students were encouraged to grapple with complex, challenging issues and, in return, work to strengthen their sociological imaginations throughout this flipped class. In addition to their reports on the value of dialoguing across difference, we, as instructors, observed that this flipped format encouraged group dialogue. The collective learning process aided in the strengthening of students' sociological imagination.

\section{Conclusions}

These data suggest that the flipped classroom provided a vehicle for our students to engage with learning goals meaningfully and was particularly helpful for meeting Learning Goals One and Five. This is not surprising, as both of those learning goals were rooted in active learning, which the course structure of a flipped classroom accommodates very well. We learned a great deal from previous literature on flipped classrooms and saw that our findings 
pointed to many of the same conclusions. This one response summarises and highlights all how we were able to encourage students to engage with all our learning goals:

I learned how to use my sociological imagination to think about the world around me - how people act and interact, how systems are set up, how structure and agency are complicated aspects of every situation. I learned a lot about several specific areas of sociological research, such as the housing market with Matt Desmond's book, and the process of masculinity with C. J. Pascoe's book. I also learned about topics such as gender, poverty and race in a broader context. I loved hearing the guest speakers talk about their research and learning how sociology is applied in the real world.

This engagement was facilitated by the flipped classroom structure, which allowed students to collaborate in dynamic, active learning activities that reinforced course learning goals. Because the flipped classroom design allows for a significant amount of in-class time for group work and exploration of complex concepts, we feel that students in this course were given more time to practice 'flexing' their sociological imagination.

In the future, we hope more scholars will explore the impacts of implementing a flipped classroom in a sociology course, with specific attention to how this course design encourages the development of the sociological imagination. There are significant limitations with the data we collected, primarily because it focuses mainly on students' perceptions and a single semester. We encourage future studies to expand on previous findings and look toward other methods of evaluation. We also encourage studies that take a more comparative and longitudinal look at flipping the classroom.

In addition to the limitations of our assessment data, there are practical limitations to consider when designing a flipped classroom. Finding an adequate space on campus to house seventy students who needed to get into breakout groups was difficult. Other scholars (Baepler et al. 2014) noted that this space concern is critical to consider before beginning the design process. We also spent significantly more time on course material preparation than we would have for a traditional course. We attempted to mitigate this by building the course shell before that semester started so that we had our materials curated and posted to the online course platform beforehand. This step was critical to our overall success and ability to keep the course running. We recognise that this extra time might be a deterrent for instructors who 
are considering this method. One positive note we can give is that when we ran this course for the second time, the time we spent on preparation was close to zero. Finally, we recognise that not all instructors have access to TAs. The TAs were integral to our ability to run smaller group activities and keep up with prework submitted by students. If TAs are not available, a possible solution could be to have more advanced undergraduates serve in this role for some form of credit. It is also possible to allow the groups to operate independently by pulling some insight from the literature on team-based learning (Stein et al. 2016).

In a moment where instruction is shifting back and forth between online and in-person for health and safety reasons, this course design could be helpful. While we originally ran this course in person, it would be possible to transform this class entirely online while still upholding the 'pay to play' model, the small group meetings, and the active learning in class. With the breakout room feature available on many online platforms, the shift to virtual would help mitigate some of the space concerns we previously mentioned. Along with other scholars in the social sciences (Luna and Winters 2017; Roehling et al. 2017), we call for more evaluation of the implementation of a flipped model. While we were able to discern student's perception of learning to assess actual learning more effectively, we encourage other scholars to design a study of a flipped classroom that includes comparative data from a traditional classroom. We also encourage future research to focus on different kinds of courses at different levels of instruction. It would be interesting to know if a flipped method is more or less effective in an introductory course than in a higher-level course. We hope this preliminary attempt encourages others to try this out in their introductory courses by providing some guidelines for implementing flipped learning in the sociology classroom.

\section{Acknowledgments and funding}

We are grateful for the support and funding we received from the Center for Teaching and Learning at Brandeis University as a part of the Innovative Teaching Grant programme. We are also thankful for the continuous support provided by instructional designers at the Center for Teaching and Learning, particularly Lance Eaton. Finally, we wish to thank Charlotte Powley and Ahmed Sadiq for their help with data analysis. 
Ann Ward is a PhD candidate in Sociology at Brandeis University. Her research interests include environmental sociology, social movements, community-based research and qualitative methods. Her current research explores the youth climate movement with particular focus on the relationship between narrative, emotion and climate change. Email: agward@brandeis.edu

Aja Antoine is a PhD student at the University of California, Berkeley. Her research interests are in the causes and consequences of inequality, sociology of the body and health, as well as qualitative research methodology. Email: aantoine@brandeis.edu

Wendy Cadge is the Barbara Mandel Professor of the Humanistic Social Sciences and Professor of Sociology at Brandeis University. She teaches and writes about religion in the contemporary United States, especially as related to health care, immigration, and sexuality.

Email: wcadge@brandeis.edu

\section{References}

Auster, C. (2016), 'Blended learning as a potentially winning combination of face to face and online learning: An exploratory study', Teaching Sociology 44, no. 1: 39-48. https://doi.org/10.1177/0092055X15619217.

Baepler, P., J. D. Walker and M. Driessen (2014), 'It's not about seat time: Blending, flipping, and efficiency in active learning classrooms', Computers and Education 78: 227-236. https://doi.org/10.1016/j.compedu.2014.06.006.

Belet, M. (2018), 'The importance of relevance to student lives: The impact of content and media in Introduction to Sociology', Teaching Sociology 46, no. 3: 208-224. https:// doi.org/10.1177/0092055X17730113.

Eglitis, D, F. Buntman and D. Alexander (2016), 'Social issues and problem-based learning in sociology: Opportunities and challenges in the undergraduate classroom', Teaching Sociology 44, no. 3: 212-220. https://doi.org/10.1177/0092055X16643572.

Faust, J. L. and D. R. Paulson (1998), 'Active learning in the college classroom', Journal on Excellence in College Teaching 9, no. 2: 3-24.

FLN (Flipped Learning Network) (2014), 'The Four Pillars of F-L-I-P'T, https:// flippedlearning.org/definition-of-flipped-learning/. 
Forsey, M., M. Low and D. Glance (2013), 'Flipping the sociology classroom: Towards a practice of online pedagogy', Journal of Sociology 49, no. 4: 471-485. https://doi.org/ 10.1177/1440783313504059.

Fuster, B. (2016), 'Negotiating the many definitions of hybrid, online classes', US News 15 January.

Heyborne, W. and J. Perrett (2016), 'To flip or not to flip? Analysis of a flipped classroom pedagogy in a general biology course', Journal of College Science Teaching 45, no. 4: 31-37. https://doi.org/10.2505/4/jcst16_045_04_31.

Horn, M. (2013), 'The transformational potential of the flipped classroom: Different strokes for different folks', Education Next 13, no. 3: 78-79, https://www.educationnext.org/ the-transformational-potential-of-flipped-classrooms/.

Howard, J., K. Novak, K. Cline and M. Scott (2014), 'Another nibble at the core', Teaching Sociology 42, no. 3: 177-186. https://doi.org/10.1177/0092055X14527422.

King, A. (1993), 'From sage on the stage to guide on the side', College Teaching 41, no. 1: 30-35. https://doi.org/10.1080/87567555.1993.9926781.

Luna, Y. and S. Winters (2017), “"Why did you blend my learning?” A comparison of student success in lecture and blended learning introduction to sociology courses', Teaching Sociology 5, no. 2:116-130. https://doi.org/10.1177/0092055X16685373.

McNally, B., J. Chipperfield, P. Dorsett, L. Del Fabbro, V. Frommolt S. Goetz, J. Lewohl, M. Molineux, A. Pearson, G. Reddan, A. Roiko and A. Rung (2017), 'Flipped classroom experiences: Student preferences and flip strategy in a higher education context', Higher Education: The International Journal of Higher Education Research 73, no. 2: 281-298. https://doi.org/10.1007/s10734-016-0014-z.

Mount, L. (2018), 'Teaching in unfamiliar terrain: Empowering student and teacher learning through a photography assignment', Teaching Sociology 46, no. 1: 54-56. https:// doi.org/10.1177/0092055X17725131.

Naccarato, E. and G. Karakok (2015), 'Expectations and implementations of the flipped classroom model in undergraduate mathematics courses', International Journal of Mathematical Education in Science and Technology 46, no. 7: 968-978. https://doi.org/ 10.1080/0020739X.2015.1071440.

Roehling, P. V., L. M. Root Luna, F. J. Richie and J. J. Shaughnessy (2017), 'The benefits, drawbacks, and challenges of using the flipped classroom in an Introduction to Psychology course', Teaching of Psychology 44, no. 3: 183-192. https://doi.org/ 10.1177/0098628317711282.

Sardi, L. M. (2018), 'Flipped classroom activity using the PTA model in an introductory sociology course', Prompt: A Journal of Academic Writing Assignments 2, no.1: 38-47. https://doi.org/10.31719/pjaw.v2i1.19.

Schwartz, T. (2014), 'Flipping the statistics classroom in nursing education', The Journal of Nursing Education 53, no. 4: 199-206. https://doi.org/10.3928/ 01484834-20140325-02. 


\section{Ann Ward, Aja Antoine and Wendy Cadge}

Stein, R. E., C. J. Colyer and J. Manning (2016), 'Student accountability in team-based learning classes', Teaching Sociology 44, no. 1: 28-38. https://doi.org/10.1177/ $0092055 X 15603429$.

Svinicki, M. (2013), 'Flipped classrooms: old or new?', National Teaching and Learning Forum Newsletter 22, no. 5: 12.

Tomory, A. and S. Watson (2015), 'Flipped classrooms for advanced science courses', Journal of Science Education and Technology 24, no. 6: 875-887.

Whitaker, J. (2017), 'Recursive exercises to help students engage and recognize sociological shifts', Teaching Sociology 45, no. 1: 14-27. 